\title{
Prognostic significance of sealed-off perforation in colon cancer: a prospective cohort study
}

\author{
Kil-yong Lee ${ }^{1}$, Ji Won Park ${ }^{1,2}$, Inho Song ${ }^{1}$, Ki-young Lee ${ }^{1}$, Sangsik Cho ${ }^{1}$, Yoon-Hye Kwon ${ }^{1}$, Min Jung Kim¹, \\ Seung-Bum Ryoo', Seung-Yong Jeong ${ }^{1,2}$ and Kyu Joo Park ${ }^{1}$
}

\begin{abstract}
Background: Perforated colon cancer is a rare complication, but has a high risk of recurrence. However, most studies have not distinguished sealed-off perforation from free perforation, and the prognosis is unclear. The aim of this study was to evaluate the oncologic outcome of colon cancer with sealed-off perforation.

Methods: Eighty-six consecutive patients who underwent resection for colon cancer with sealed-off or free perforation were included. We defined sealed-off perforation as a colon perforation with localized abscess identified on operative, computed tomography, or pathologic findings, with no evidence of free perforation, including fecal contamination and dirty fluid collection in the peritoneal cavity. Oncologic outcomes were compared between patients with colon cancer with sealed-off perforation and free perforation using a log-rank test and Cox regression analysis.

Results: The sealed-off perforation group included 62 patients, and 24 patients were in the free perforation group. TNM stage and lymphatic, venous, and perineural invasion were similar between the groups. The median follow-up period was 28.9 months (range 0-159). The sealed-off perforation group had better prognosis compared with the free perforation group in terms of progression-free survival (PFS) and overall survival (OS), although there were no statistically significant differences in PFS (5-year PFS 53.7\% vs. 40.5\%, $p=0.148 ; 5$-year OS $53.6 \%$ vs. $22.9 \%, p=0.001$ ). However, in multivariable analysis using the Cox progression test, sealed-off perforation did not show a significant effect on cancer progression ( $p=0.138)$ and OS ( $p=0.727$ ).
\end{abstract}

Conclusions: Colon cancer with sealed-off perforation showed no difference in prognosis compared with free perforation.

Keywords: Sealed-off perforation, Free perforation, Colon cancer

\section{Introduction}

The prevalence of perforation in colon cancer patients is reported to be $3-10 \%[1-3]$. More specifically, colon cancer patients with perforation exhibit a greater frequency of recurrence and poorer overall survival (OS) compared with those without perforation $[4,5]$. In the National Comprehensive Cancer Network guidelines, colon cancer with perforation is categorized a high-risk feature [6].

\footnotetext{
* Correspondence: sowisdom@gmail.com

${ }^{1}$ Department of Surgery, Seoul National University College of Medicine, 101 Daehak-ro, Jongno-gu, Seoul, South Korea

${ }^{2}$ Cancer Research Institute, Seoul National University College of Medicine, Seoul, South Korea
}

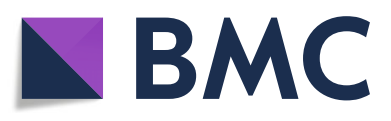

(c) The Author(s). 2018 Open Access This article is distributed under the terms of the Creative Commons Attribution 4.0 International License (http://creativecommons.org/licenses/by/4.0/), which permits unrestricted use, distribution, and

reproduction in any medium, provided you give appropriate credit to the original author(s) and the source, provide a link to the Creative Commons license, and indicate if changes were made. The Creative Commons Public Domain Dedication waiver (http://creativecommons.org/publicdomain/zero/1.0/) applies to the data made available in this article, unless otherwise stated.

Perforations caused by colon cancer appear as free or sealed-off perforations. A previous study reported that local inflammation affects the prognosis of colorectal cancer [7]; therefore, sealed-off perforation is suspected to exhibit oncological outcomes different from those of free perforation, due to local inflammation caused by the formation of localized abscess. Furthermore, unlike cases of free perforation in which the possibility of tumor dissemination is high, cases of sealed-off perforation prevent tumor spread due to the formation of an abscess cavity. Therefore, sealed-off perforation is expected to have better prognosis compared with free perforation. To the best of our knowledge, no prior study has assessed the prognostic difference in colon cancer patients with free or sealed-off perforation. 
This study divided patients into free and sealed-off groups to assess differences in baseline characteristics and whether sealed-off or free perforations have different effects on oncological outcomes.

\section{Method}

Subjects in this study were pathologically diagnosed with primary colon cancer and received surgical treatment at Seoul National University Hospital between March 2002 and August 2017. The inclusion criterion was the presence of either free or sealed-off perforation. The exclusion criteria were history of other malignancy, other accompanying malignancy, and endoscopic or stent-related perforation.

We defined sealed-off perforation as a colon perforation with localized abscess identified on operative computed tomography or pathologic examination, with no evidence of free perforation including fecal contamination and dirty fluid collection in the peritoneal cavity.

Data collected were retrospectively reviewed. Patient clinical characteristics, operative outcomes, pathologic examination results, and postoperative chemotherapy, complications, and mortality were assessed. Complications were classified using the Clavien-Dindo classification. Patients without metastasis were assessed for recurrence while patients with metastasis were assessed for progression.

Study approval was obtained from Seoul National University Hospital Institutional Review Board (IRB).

\section{Follow-up}

The patient was discharged if the following conditions were met: postoperative vital signs were stable, no abnormalities were observed on physical examination, no sign of inflammation was observed on laboratory examination, and no dietary issues were present. Stage II and III patients were asked to return for follow-up visits every 6 months for the first 2 years. To detect potential recurrences in these patients, a carcinoembryonic antigen (CEA) test was performed every 6 months; chest, abdomen, and pelvic computed tomography (CT) were performed annually, and colonoscopy was performed every 6-12 months. Stage IV patients attended regular follow-up visits every 3 months. These patients had CEA every 3 months, CT every 3-6 months, and colonoscopy every year to assess possible recurrence.

\section{Outcome}

The primary end-point of this study was progression-free survival (PFS), and the secondary outcome was local recurrence-free survival (LRFS), peritoneal recurrence-free survival (PRFS), and overall survival. PFS was defined as the time between the date of surgery and the date of diagnosis, cancer progression, or death from any cause. LRFS was defined at the time between the date of surgery and the date of diagnosis of local recurrence, cancer progression, or death from any cause. PRFS was defined at the time between the date of surgery and the date of diagnosis of peritoneal recurrence, cancer progression, or death from any cause. OS was defined as the time period between the date of surgery and the date of death from any cause. When we performed the survival analysis, patients who died within 30 days after surgery were excluded to focus on oncologic outcomes.

\section{Statistical analysis}

To compare baseline characteristics between the free and sealed-off perforation groups, the chi-squared test, Fisher's exact test, and linear-by-linear association method were used as categorical variables, while the independent $t$ test or Mann-Whitney test were used for continuous variables, based on normality of data.

To compare PFS and OS, the Kaplan-Meier method (including log-rank test) was used to perform survival analysis. Cox proportional hazards regression was used to identify independent factors affecting PFS and OS.

Furthermore, the propensity score matching was performed with 1:1 ratio between two groups using logistic regression as estimation algorithm and the nearest neighbor as the matching algorithm. Covariables used in the matching were age, sex, ASA classification, BMI, stage, and postoperative chemotherapy.

Statistical tests were performed using the statistical package for the social sciences (SPSS) version 25.0 for windows (IBM Corp, Armonk, NY, USA), and $p<0.05$ was considered statistically significant.

\section{Results}

Of 5823 patients who received surgical treatment for primary colon cancer at Seoul National University Hospital, 108 had colonic perforation. After excluding patients with perforations caused by stenting or colonoscopy and those with perforations distant from the tumor, 86 patients were included in the final study cohort. Of these, 24 had a free perforation and 62 had a sealed-off perforation (Fig. 1). The median follow-up was 28.9 months (range 0-159 months).

Baseline patient characteristics are shown in Table 1. Patients in the free perforation group were older than those in the sealed-off perforation group (76.1 \pm 12.5 vs. $59.4 \pm 15.5$ years). In addition, the free perforation group had more patients with higher American Society of Anesthesiologists (ASA) class and fewer received postoperative chemotherapy (29.2\% vs. $74.2 \%)$. Emergency operation was performed more frequently in the free perforation group. $(91.7 \%$ vs $22.6 \%, p=0.000)$. The rate of postoperative complications in the free perforation group was statistically significantly higher than that in the sealed-off perforation group (Table 1). The duration of hospital stay was longer in the free perforation group 

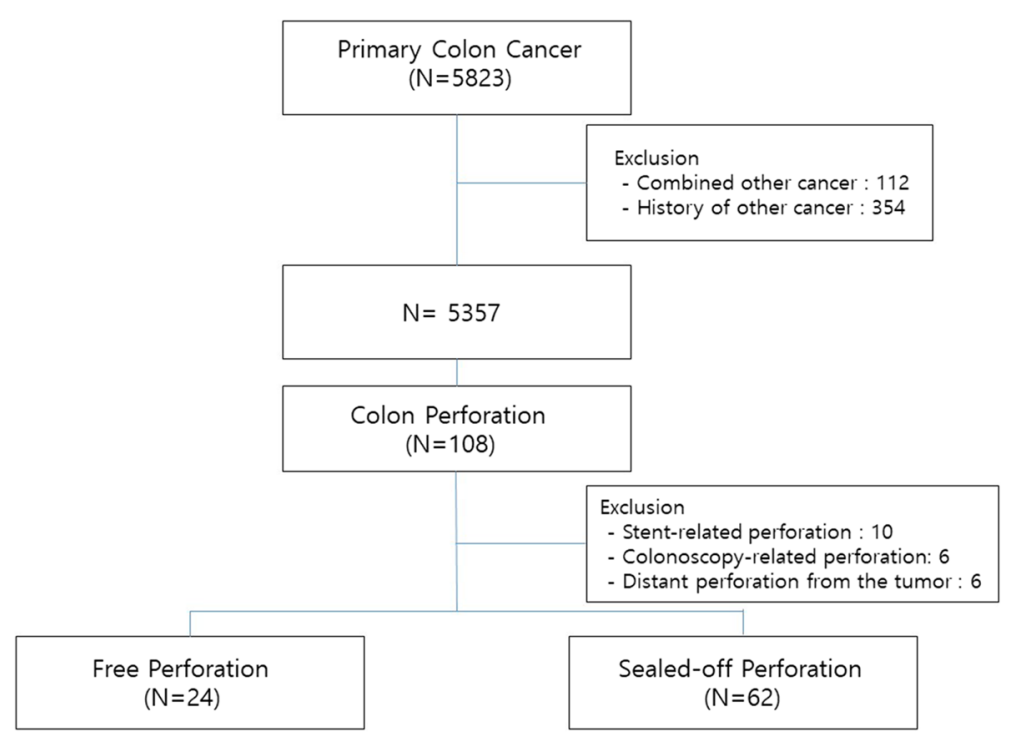

Fig. 1 Flow chart of patient selection

than in the sealed-off perforation group, but the difference was not statistically significant $(17.4 \pm 14$.2 days vs. $12.0 \pm 12.3$ days, $p=0.062$ ). The 30 -day mortality did not differ statistically but was higher in the free perforation group than in the sealed-off perforation group $(12.5 \%$ vs. $1.6 \%, p=0.064)$.

The median PFS durations for the free and sealed-off perforation groups were 13.8 months (range $0-83$ months) and 27.9 months (range $0-159$ ), respectively, with a 5 -year PFS of $40.5 \%$ and $53.7 \%$. The sealed-off perforation group displayed a better trend in the Kaplan-Meier curve. However, the log-rank test did not show statistically significant differences between the groups $(p=0.148)$ (Fig. 2b). LRFS and PRFS according to the type of recurrence were analyzed. Five-year LRFS of $75.8 \%$ and $84.0 \%$ and 5 -year PRFS of $75.0 \%$ and $94.7 \%$ were observed between free and sealed-off perforation groups. The sealed-off perforation group appeared to have a better prognosis in terms of LRFS and PRFS (Fig. 2b, c). However, there was no significant difference between the two groups in the log-rank test (LRFS, $p=0.315$; PRFS, $p=0.069$ ).

The median OS durations for the free and sealed-off groups were 19.6 months (range $0-84$ ) and 49.3 months (range 0-181) respectively, with a 5 -year OS of $22.9 \%$ and $53.6 \%$. The sealed-off perforation group appeared to have a better prognosis (Fig. 2d). There was a significant difference between the two groups in the log-rank test $(p=0.001)$.

Cox proportional hazards regression was performed to identify the factors associated with cancer progression. Several factors including ASA class $3(p=0.024)$, tumor size $(p=0.005)$, and T stage $(p=0.043)$ affected cancer progression, but sealed-off perforation did not show a significant effect on cancer progression $(p=0.138)$ (Table 2).

In an analysis to identify risk factors for OS, ASA class $(p=0.011)$ and major postoperative complications $(p=$ $0.049)$ were statistically significant. However, the presence of sealed-off perforation was not a factor affecting OS $(p=0.727)$ (Table 3$)$.

We performed propensity score matching by adjusting for age, sex, ASA class, BMI, stage, and postoperative chemotherapy between the two groups (Additional file 1: Table S1). However, there was no difference in PFS $(p=0.604)$, LRFS $(p=0.919)$, PRFS $(p=0.323)$, and OS $(p=0.062)$ between the two groups (Additional file 2: Figure S A-D). Furthermore, the perforation type did not appear to be a factor affecting PFS (HR 0.565, 95\% CI 0.000-1500.805) and OS (HR 12.930, 95\% CI 0.1311053.246) (Additional file 1: Tables S2 and S3).

\section{Discussion}

This study demonstrated that primary colon cancer patients with sealed-off perforation did not have a better prognosis in PFS and OS compared to patients with free perforation, although the Kaplan-Meier curves with log rank test for overall survival showed a statistically significant difference. Perforation type was not a risk factor for PFS and OS although propensity score matching was performed to correct the differences in baseline characteristics between the two groups.

Colon cancer perforation is known to have a poor prognosis, not only because it frequently occurs in advanced stage cancers but also because perforation itself 
Table 1 Baseline characteristics

\begin{tabular}{|c|c|c|c|}
\hline & $\begin{array}{l}\text { Free perforation } \\
(n=24)\end{array}$ & $\begin{array}{l}\text { Sealed-off perforation } \\
(n=62)\end{array}$ & $p$ value \\
\hline Age (years old) & $76.1 \pm 12.5$ & $59.4 \pm 15.5$ & 0.000 \\
\hline Sex & & & 0.874 \\
\hline Male & $14(58.3 \%)$ & $35(56.5 \%)$ & \\
\hline Female & $10(41.7 \%)$ & $27(43.5 \%)$ & \\
\hline BMI $\left(\mathrm{kg} / \mathrm{m}^{2}\right)$ & $22.7 \pm 3.5$ & $22.0 \pm 2.8$ & 0.458 \\
\hline ASA class & & & 0.001 \\
\hline 1 & $4(19.0 \%)$ & $26(44.8 \%)$ & \\
\hline 2 & $8(38.1 \%)$ & $26(44.8 \%)$ & \\
\hline 3 & $8(38.1 \%)$ & $6(10.3 \%)$ & \\
\hline 4 & $1(4.8 \%)$ & $0(0 \%)$ & \\
\hline Surgery & & & 0.000 \\
\hline Elective & $2(8.3 \%)$ & $48(77.4 \%)$ & \\
\hline Emergency & $22(91.7 \%)$ & $14(22.6 \%)$ & \\
\hline Operation intent & & & 0.752 \\
\hline Curative & $19(79.2 \%)$ & $52(83.9 \%)$ & \\
\hline Palliative & $5(20.8 \%)$ & $10(16.1 \%)$ & \\
\hline Tumor differentiation & & & 0.858 \\
\hline Adenocarcinoma, well differentiated & $1(4.2 \%)$ & $3(4.8 \%)$ & \\
\hline Adenocarcinoma, moderate differentiated & $19(79.2 \%)$ & $48(77.4 \%)$ & \\
\hline Adenocarcinoma, poorly differentiated & $3(12.5 \%)$ & $8(12.9 \%)$ & \\
\hline Mucinous carcinoma & $1(4.2 \%)$ & $2(3.2 \%)$ & \\
\hline Signet ring cell carcinoma & $0(0.0 \%)$ & $1(1.6 \%)$ & \\
\hline Size $(\mathrm{cm})$ & $5.8 \pm 2.3$ & $6.6 \pm 2.3$ & 0.100 \\
\hline pT & & & 0.687 \\
\hline 3 & $12(50.0 \%)$ & $28(45.2 \%)$ & \\
\hline 4 & $12(50.0 \%)$ & $34(54.8 \%)$ & \\
\hline $\mathrm{pN}$ & & & 0.779 \\
\hline 0 & $10(41.7 \%)$ & $27(43.5 \%)$ & \\
\hline 1 & $11(45.8 \%)$ & $23(37.1 \%)$ & \\
\hline 2 & $3(12.5 \%)$ & $12(19.4 \%)$ & \\
\hline The number of metastatic LN & $1.5 \pm 2.9$ & $2.2 \pm 3.8$ & 0.325 \\
\hline The number of harvest $L N$ & $18.9 \pm 9.5$ & $23.3 \pm 11.4$ & 0.091 \\
\hline M & & & 0.588 \\
\hline 0 & $16(66.7 \%)$ & $45(72.6 \%)$ & \\
\hline 1 & $8(33.3 \%)$ & $17(27.4 \%)$ & \\
\hline Proximal margin $(\mathrm{cm})$ & $27.5 \pm 30.2$ & $19.5 \pm 20.4$ & 0.088 \\
\hline Distal margin $(\mathrm{cm})$ & $13.9 \pm 14.5$ & $10.7 \pm 9.5$ & 0.395 \\
\hline Lymphatic invasion & & & 0.848 \\
\hline Absent & $13(54.2 \%)$ & $35(56.5 \%)$ & \\
\hline Present & $11(45.8 \%)$ & $27(43.5 \%)$ & \\
\hline Venous invasion & & & 0.161 \\
\hline Absent & $15(62.5 \%)$ & $45(77.6 \%)$ & \\
\hline Present & $9(37.5 \%)$ & $13(22.4 \%)$ & \\
\hline
\end{tabular}


Table 1 Baseline characteristics (Continued)

\begin{tabular}{lll}
\hline & $\begin{array}{l}\text { Free perforation } \\
(n=24)\end{array}$ & $\begin{array}{l}\text { Sealed-off perforation } \\
(n=62)\end{array}$ \\
\hline $\begin{array}{l}\text { Perineural invasion } \\
\text { Absent }\end{array}$ & $17(70.8 \%)$ & $37(63.8 \%)$ \\
Present & $7(29.2 \%)$ & $21(36.2 \%)$ \\
Postoperative complication & & \\
(Clavien-Dindo classification) & & \\
No complication & $9(37.5 \%)$ & $50(42.5 \%)$ \\
Grade I & $2(8.3 \%)$ & $0(0 \%)$ \\
Grade II & $4(16.7 \%)$ & $8(12.9 \%)$ \\
Grade III & $5(20.8 \%)$ & $3(4.8 \%)$ \\
Grade IV & $4(16.7 \%)$ & $1(1.6 \%)$ \\
Postoperative chemotherapy & $7(29.2 \%)$ & $46(74.2 \%)$ \\
\hline
\end{tabular}

$B M I$ body mass index, ASA class American Society of Anesthesiologists classification, $L N$ lymph nodes
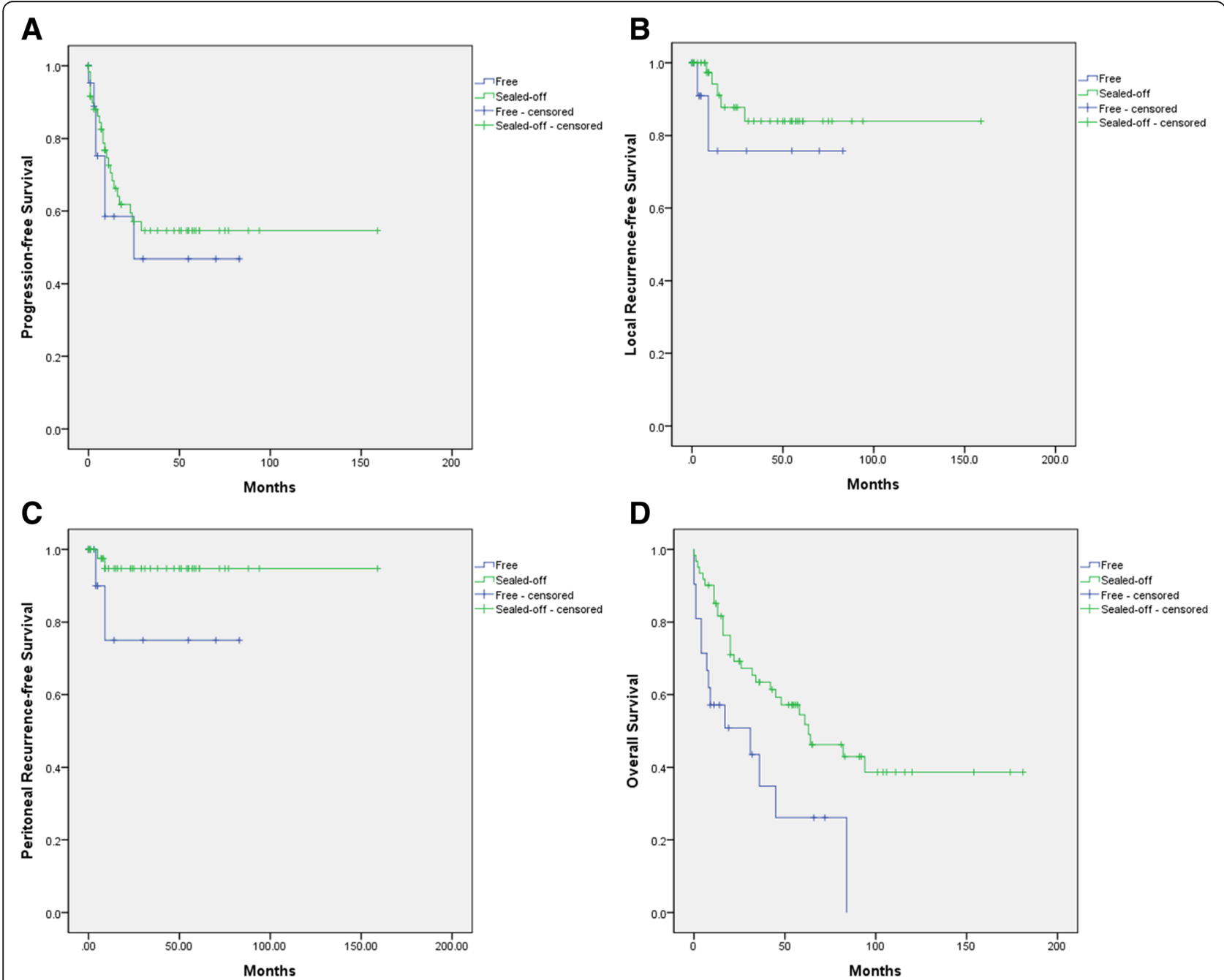

Fig. 2 Kaplan-Meier curves between sealed-off (green line) and free perforation (blue line). a Progression-free survival. b Local recurrence-free survival. c Peritoneal recurrence-free survival. d Overall survival 
Table 2 Risk factors associated with cancer progression

\begin{tabular}{|c|c|c|c|}
\hline & Hazard ratio & 95\% confidence interval & $p$ value \\
\hline Age (years old) & 0.986 & $0.940-1.033$ & 0.545 \\
\hline Sex (female) & 2.039 & $0.677-6.141$ & 0.205 \\
\hline ASA class & & & 0.057 \\
\hline 1 & 1 (reference) & 1 (reference) & \\
\hline 2 & 0.914 & $0.237-3.523$ & 0.897 \\
\hline 3 & 8.192 & $1.313-51.120$ & 0.024 \\
\hline BMI $\left(\mathrm{Kg} / \mathrm{m}^{2}\right)$ & 1.079 & $0.888-1.310$ & 0.444 \\
\hline Sealed-off perforation & 0.443 & $0.151-1.300$ & 0.138 \\
\hline Emergency operation & 0.082 & $0.008-0.864$ & 0.037 \\
\hline Palliative & 2.867 & $0.423-19.450$ & 0.281 \\
\hline Size $(\mathrm{cm})$ & 1.483 & $1.074-2.046$ & 0.017 \\
\hline pT & & & 0.012 \\
\hline 3 & 1 (reference) & 1 (reference) & \\
\hline 4 & 10.657 & $1.669-68.028$ & \\
\hline $\mathrm{pN}$ & & & 0.697 \\
\hline 1 & 0.603 & $0.170-2.139$ & 0.434 \\
\hline 2 & 0.606 & $0.096-3.816$ & 0.594 \\
\hline M1 & 4.594 & $0.838-25.197$ & 0.079 \\
\hline Proximal margin $(\mathrm{cm})$ & 1.041 & $1.002-1.082$ & 0.038 \\
\hline Distal margin $(\mathrm{cm})$ & 0.949 & $0.887-1.016$ & 0.134 \\
\hline Lymphatic invasion & 1.535 & $0.514-4.568$ & 0.444 \\
\hline Venous invasion & 1.382 & $0.340-5.626$ & 0.651 \\
\hline Perineural invasion & 1.193 & $0.276-5.150$ & 0.813 \\
\hline Postoperative chemotherapy & 3.376 & $0.622-18.322$ & 0.159 \\
\hline Postoperative major complication† & 5.628 & $0.991-31.970$ & 0.051 \\
\hline
\end{tabular}

$B M I$ body mass index, ASA class American Society of Anesthesiologists classification tClavien-Dindo classification grade 3 or higher was defined as major complication

can cause septic complications [2]. More specifically, tumor perforation can cause tumor dissemination, leading to greater recurrence rate and poorer survival [8]. We expected that sealed-off perforation would result in less dissemination of malignant cells into the peritoneal cavity. However, the difference in PFS between the groups was not statistically significant. Even local recurrence and peritoneal recurrence were not different from each other. This may be due to the smaller number of patients in the free perforation group. In addition, patients in the sealedoff perforation group may exhibit tumor dissemination if the abscess cavity bursts during surgery. However, we could not assess possible rupture of an abscess cavity during dissection, which may have led to statistically non-significant outcomes. Furthermore, better trends for LRFS, PRFS, and PFS were observed in the sealed-off perforation group, although the pathologic findings (TNM stage, and lymphatic, venous, and perineural invasion) were not different between the groups, suggesting that perforation type may affect prognosis.
Although several studies reported the effects of inflammation in the local tumor environment [9-11], the effect of sealed-off perforation on local inflammation has not been sufficiently addressed. This study is the first to assess the difference in oncological prognosis between sealed-off perforation and free perforation. Nonetheless, additional studies should be performed to assess the differences in local immunity according to perforation types.

In the analysis of risk factors affecting cancer progression, $\mathrm{T}$ stages were a risk factor, but not $\mathrm{N}$ stages. We suspect that $\mathrm{N}$ stages could not be identified as risk factors because of the small number of enrolled patients. Poorer OS in the free perforation group compared to the sealed-off perforation group is likely due to older age, greater frequency of comorbidities, and postoperative morbidity. Univariable analysis for OS further supports this hypothesis. The baseline characteristics of free perforation patients were older age, greater frequency of comorbidity, and lower frequency of postoperative chemotherapy. Therefore, we could not narrow the 
Table 3 Risk factors for overall survival

\begin{tabular}{|c|c|c|c|}
\hline & Hazard ratio & 95\% confidence interval & $p$ value \\
\hline Age (years old) & 1.034 & $0.998-1.071$ & 0.068 \\
\hline Sex (female) & 0.839 & $0.350-2.012$ & 0.694 \\
\hline $\mathrm{BMI}\left(\mathrm{kg} / \mathrm{m}^{2}\right)$ & 0.927 & $0.811-1.059$ & 0.265 \\
\hline ASA class & & & 0.011 \\
\hline 1 & 1 (reference) & 1 (reference) & \\
\hline 2 & 0.465 & $0.16-1.320$ & 0.150 \\
\hline 3 & 3.503 & $0.977-12.563$ & 0.054 \\
\hline Sealed-off perforation & 0.759 & $0.162-3.554$ & 0.727 \\
\hline Emergency operation & 0.694 & $0.171-2.812$ & 0.609 \\
\hline Palliative & 2.340 & $0.520-10.532$ & 0.268 \\
\hline Size $(\mathrm{cm})$ & 0.886 & $0.724-1.084$ & 0.239 \\
\hline pT & & & 0.025 \\
\hline 3 & 1 (reference) & 1 (reference) & \\
\hline 4 & 3.480 & $1.174-10.318$ & \\
\hline $\mathrm{pN}$ & & & 0.546 \\
\hline 0 & 1 (reference) & 1 (reference) & \\
\hline 1 & 1.029 & $0.430-2.461$ & 0.950 \\
\hline 2 & 2.168 & $0.538-8.747$ & 0.277 \\
\hline M1 & 4.766 & $1.432-15.860$ & 0.011 \\
\hline Proximal margin $(\mathrm{cm})$ & 1.009 & $0.986-1.032$ & 0.440 \\
\hline Distal margin $(\mathrm{cm})$ & 1.013 & $0.972-1.057$ & 0.535 \\
\hline Venous invasion & 1.013 & $0.246-2.199$ & 0.583 \\
\hline Lymphatic invasion & 1.541 & $0.614-3.862$ & 0.357 \\
\hline Perineural invasion & 2.225 & $0.754-6.569$ & 0.148 \\
\hline Postoperative chemotherapy & 0.562 & $0.188-1.677$ & 0.302 \\
\hline Postoperative major complication† & 3.931 & $1.009-15.319$ & 0.049 \\
\hline
\end{tabular}

BMI body mass index, ASA class American Society of Anesthesiologists classification +Clavien-Dindo classification grade 3 or higher was defined as major complication

difference between two groups even after propensity score matching.

Postoperative chemotherapy was performed significantly more often in the sealed-off perforation group. Relatively higher ASA class and older age of patients in the free perforation group can explain this finding.

There were several limitations in this study. First, the retrospective design may have introduced selection bias and possibly some errors during data extraction. Second, type II error is a possibility since the number of patients with free perforation was smaller than the number with sealed-off perforation.

In conclusion, colon cancer with sealed-off perforation showed no difference in prognosis compared with free perforation even after propensity score matching was performed. Considering the limitations of a small number of patients and unbalanced patient distribution, additional studies with larger cohort should be performed to assess the effect of sealed-off perforation on local immunity.

\section{Additional files}

Additional file 1: Table S1 Clinicopathologic characteristics after propensity score matching. Table S2 Risk factors associated with cancer progression after propensity score matching. Table S3 Risk factors for overall survival after propensity score matching. (DOCX 21 kb)

Additional file 2: Kaplan-Meier curves between sealed-off (green line) and free perforation (blue line) after propensity score matching. (a) local recurrence-free survival. (b) peritoneal recurrence-free survival. (c) progression-free survival. (d) Overall survival. (PNG 51 kb)

\section{Acknowledgements}

Not applicable.

Funding

Not applicable.

\section{Availability of data and materials}

All data generated or analyzed during this study are included in this published article. 


\section{Authors' contributions}

KYL, MJK, IHS, and JWP analyzed and interpreted the patient data regarding perforated colon cancer. KiYL, SSC, and YHK collected the data. JWP, SBR, SYJ, and KJP performed the operation and followed up the patients. KYL was a major contributor in writing the manuscript. All authors read and approved the final manuscript.

\section{Ethics approval and consent to participate}

The study was performed in accordance with the declaration of Helsinki and was approved by the Seoul National University Hospital Institutional Review Board (IRB).

\section{Consent for publication}

Not applicable.

\section{Competing interests}

The authors declare that they have no competing interests.

\section{Publisher's Note}

Springer Nature remains neutral with regard to jurisdictional claims in published maps and institutional affiliations.

Received: 17 August 2018 Accepted: 20 November 2018

Published online: 04 December 2018

\section{References}

1. Biondo S, Martí-Ragué J, Kreisler E, et al. A prospective study of outcomes of emergency and elective surgeries for complicated colonic cancer. Am J Surg. 2005;189:377-83.

2. Crowder VH Jr, Cohn I Jr. Perforation in cancer of the colon and rectum. Dis Colon Rectum. 1967;10:415-20.

3. McGregor JR, O'Dwyer PJ. The surgical management of obstruction and perforation of the left colon. Surg Gynecol Obstet. 1993;177:203-8.

4. Chen TM, Huang YT, Wang GC. Outcome of colon cancer initially presenting as colon perforation and obstruction. World J Surg Oncol. 2017:15:164.

5. Liska D, Stocchi L, Karagkounis G, et al. Incidence, patterns, and predictors of locoregional recurrence in colon cancer. Ann Surg Oncol. 2017:24:1093-9.

6. Benson AB, Venook AP, Cederquist $L$, et al. Colon cancer, version 1.2017, NCCN clinical practice guidelines in oncology. J Natl Compr Cancer Netw 2017;15:370-398

7. Roxburgh CS, McMillan DC. The role of the in situ local inflammatory response in predicting recurrence and survival in patients with primary operable colorectal cancer. Cancer Treat Rev. 2012;38:451-66.

8. Carraro PG, Segala M, Orlotti C, et al. Outcome of large-bowel perforation in patients with colorectal cancer. Dis Colon Rectum. 1998;41:1421-6.

9. Diakos $\mathrm{Cl}$, Charles KA, McMillan DC, et al. Cancer-related inflammation and treatment effectiveness. Lancet Oncol. 2014;15:2493-503.

10. Mantovani A, Allavena P, Sica A, et al. Cancer-related inflammation. Nature. 2008:454:436-44

11. Shalapour S, Karin M. Immunity, inflammation, and cancer: an eternal fight between good and evil. J Clin Invest. 2015;125:3347-55.

Ready to submit your research? Choose BMC and benefit from:

- fast, convenient online submission

- thorough peer review by experienced researchers in your field

- rapid publication on acceptance

- support for research data, including large and complex data types

- gold Open Access which fosters wider collaboration and increased citations

- maximum visibility for your research: over $100 \mathrm{M}$ website views per year

At $\mathrm{BMC}$, research is always in progress.

Learn more biomedcentral.com/submissions 